\title{
How to prevent SAM in mitral valve reconstruction
}

\author{
M Cocora*, D Nechifor \\ From 23rd World Congress of the World Society of Cardio-Thoracic Surgeons \\ Split, Croatia. 12-15 September 2013
}

\section{Background}

SAM is a life threatening condition with up to $20 \%$ risk of sudden death. The present study analyses the mitral reconstructions performed by the authors during the last 5 years, from the point of view of preoperative risk for SAM, the appearance rate of post operative SAM and the ways of dealing with it.

\section{Methods}

We present a retrospective study on 120 cases with degenerative mitral regurgitation in which surgical mitral reconstruction has been tried in the last 5 years. 29 Barlow diseases, 50 FED, 20 idiopathic calcification of PML. Preoperative echographic and intraoperative valve analysis reveals risks factors for SAM; small LV, bulging septum, redundant leaflets, reduced mitro aortic angle, anterior coaptation line. All patients were operated with classical approach, median sternotomy, CEC, standard techniques for mitral valve reconstruction. Surgical methods for SAM prevention are; rings of corresponding dimensions, avoidance of large quadrangular resections, reconstruction of correct ratio between PML and AML dimensions by annular sliding; for large PML prefers the chordae insertion or butterfly resection.

\section{Results}

The incidence in patients with high risk of SAM in the pathology approached was $15 \%$.The incidence of post operative SAM was 3\% related to the whole pathology approached or $16 \%$ related to the group of patients with high risk of SAM.33\% of patients with postoperative SAM were treated by pharmacological maneuvers, the rest requiring surgical reconstruction, with a death rate $25 \%$ despite surgical treatment.

* Correspondence: mcocora@cardiologie.ro

IBCV Timisoara, Timisoara, Romania

\section{Conclusion}

Intraoperative TEE and valve analysis delimitates a group of patients with high risk of post operative SAM. The attention for the prevention of SAM led to the lowering of its incidence. $30 \%$ of post operative SAM was efficiently controlled by pharmacological maneuvers.

Published: 11 September 2013

doi:10.1186/1749-8090-8-S1-0272

Cite this article as: Cocora and Nechifor: How to prevent SAM in mitral valve reconstruction. Journal of Cardiothoracic Surgery 2013 8(Suppl 1): $\mathrm{O} 272$.
Submit your next manuscript to BioMed Central and take full advantage of:

- Convenient online submission

- Thorough peer review

- No space constraints or color figure charges

- Immediate publication on acceptance

- Inclusion in PubMed, CAS, Scopus and Google Scholar

- Research which is freely available for redistribution
() Biomed Central 